\title{
Morphometric Analysis of the Human Cervical Motoneurons in the Aging Process
}

\author{
By \\ Hu YUAN, Noboru GOTO, Hiroshi AKITA, Naoki SHIRAISHI and Hui-Jing HE \\ Department of Anatomy, Showa University School of Medicine, Tokyo 142-8555, Japan
}

- Received for Publication, November 2, 1999 -

\begin{abstract}
Key Words: Anatomy, Anterior horn cell, Atrophy, Senile change, Spinal cord
Summary: We examined 12 human cervical spinal cords to study the numbers and transverse cell body areas of the motoneurons in relation to the aging process. Our conclusion was that cervical motoneurons regulate their function by increasing in size to compensate the loss in numbers that occur as people get older.
\end{abstract}

There have been few morphometric studies of age-related changes affecting the nervous system, especially the human spinal cord. Studies so far have dealt with the length and caudal level of termination $^{4}$, atrophic changes ${ }^{2,9)}$, or the decrease in the total number of motoneurons in the spinal cord $^{5,6,8)}$. Quantitative studies on both the number and the transverse area of motoneurons were conducted by Zhang et al. ${ }^{9)}$ They presented exceptionally reliable data thanks to the use of a new preparation method ${ }^{3)}$ that reduces the shrinkage ratio to about $10 \%$.

Their study showed that the number and transverse area of motoneurons at $\mathrm{C}_{6}$ level of the human spinal cord decreases with age. The present study was undertaken to make quantitative analysis of the motoneurons at different ages, and to see if the reduction in the number, average area and total area of the motoneurons (Rexed's Lamina IX) in the human cervical spinal cord (from $C_{1}$ to $C_{8}$ ) occurs during the aging process.

\section{Methods}

We examined 12 male cervical spinal cords which had been removed from cadavers for anatomic dissection. The age at death ranged from 41 to 88 years (average: $63.3 \pm 14.4$ ). The causes of death were not related either directly or indirectly with the central nervous system, and no pathologic changes were found in the spinal cord on microscopic examination. Therefore, the spinal cords in our study were considered normal. For fixation, $10 \%$ formalin $(3.7 \%$ to $4.0 \%$ formaldehyde) was injected through the femoral artery using a pulsation pump; blood was drained through the bilateral femoral and jugular veins. The spinal cord was removed en bloc together with the dura mater and placed in a $10 \%$ solution of formalin. This was followed by secondary fixation with a mixed solution of $5 \%$ potassium dichromate and $5 \%$ potassium chromate $(1: 4$ in volume) for 3 weeks. Tissue blocks from the cervical spinal cord (from $\mathrm{C}_{1}$ to $\mathrm{C}_{8}$ ) were washed in running tap water, dehydrated with alcohol, embedded in celloidin, cut transversely into $20 \mu \mathrm{m}$-thick sections, and stained with the Luxol fast blue-peridic acid-Schiff-hematoxylin ${ }^{3)}$ or Klüver-Barrera methods. For the measurement and analysis of the sections, a combination of an electronic optical planimeter (Digitizer KC 3300. Graphtec Co, Japan) and a computer (PC-9821 V13, NEC, Japan) was adopted to count the total number of motoneurons in both left and right sides of the spinal cord and to measure the area of the transverse section of the motoneurons in Rexed's lamina IX at levels $C_{1}$ to $C_{8}$. The data were presented as mean \pm S.D. A linear regression analysis was performed to determine the correlation between age and the following data: number, mean 
area and total area of the motoneurons. A value of $\mathbf{P}<0.05$ was regarded as significant.

\section{Results}

Mean Number of Motoneurons

The number of motoneurons having a nucleolus in the nucleus ranged from 15 to 83 (mean:

Table 1. Mean number of motoneurons (per transverse section)

\begin{tabular}{lllllllllll}
\hline Age & $\mathrm{C}_{1}$ & $\mathrm{C}_{2}$ & $\mathrm{C}_{3}$ & $\mathrm{C}_{4}$ & $\mathrm{C}_{5}$ & $\mathrm{C}_{6}$ & $\mathrm{C}_{7}$ & $\mathrm{C}_{8}$ & mean & \pm S.D. \\
\hline 41 & 21 & 34 & 26 & 49 & 36 & 26 & 56 & 15 & 32.9 & 13.9 \\
47 & 27 & 21 & 17 & 62 & 79 & 58 & 46 & 54 & 45.5 & 22.0 \\
52 & 16 & 18 & 22 & 50 & 42 & 44 & 45 & 32 & 33.6 & 13.5 \\
54 & 46 & 39 & 36 & 45 & 41 & 46 & 55 & 72 & 47.5 & 11.4 \\
59 & 35 & 21 & 41 & 66 & 64 & 83 & 47 & 32 & 48.6 & 20.7 \\
59 & 22 & 13 & 28 & 37 & 50 & 30 & 38 & 25 & 30.4 & 11.3 \\
61 & 28 & 53 & 35 & 40 & 48 & 50 & 33 & 21 & 38.5 & 11.3 \\
65 & - & 31 & 52 & 82 & 49 & 63 & 30 & 52 & 51.3 & 18.0 \\
73 & - & 29 & 40 & 71 & 54 & 35 & 41 & 32 & 43.1 & 14.7 \\
78 & 43 & 19 & 47 & 42 & 54 & 48 & 74 & 47 & 46.8 & 15.1 \\
82 & - & 44 & 36 & 61 & 57 & 51 & 50 & 43 & 48.9 & 8.6 \\
88 & - & 28 & 22 & 42 & 22 & 21 & 18 & 48 & 28.7 & 11.6 \\
\hline
\end{tabular}

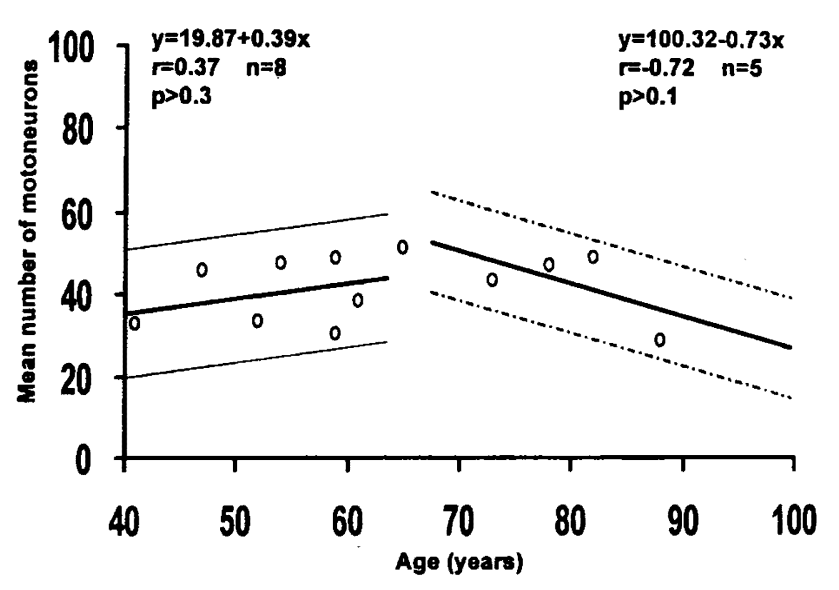

Fig. 1. Mean number of motoneurons in the human cervical cord.

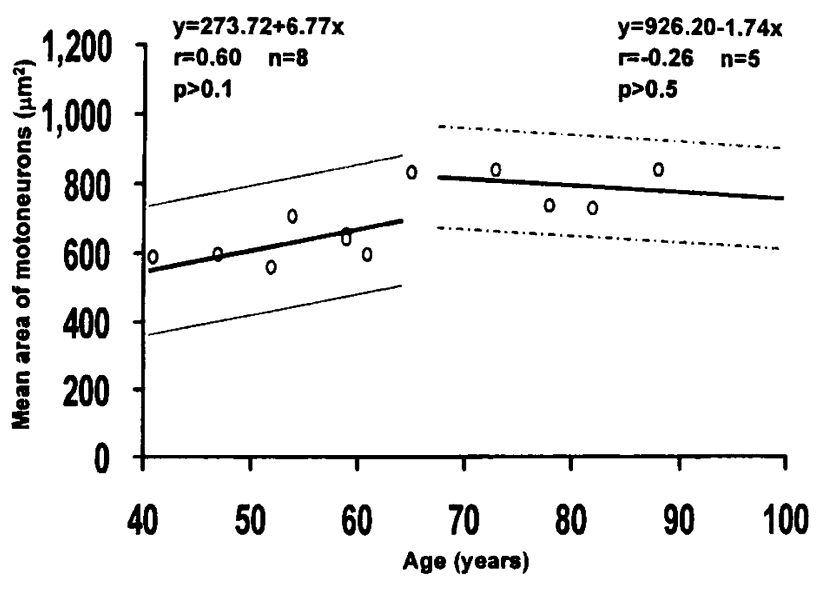

Fig. 2. Mean transverse area of motoneurons in the human cervical cord.

Table 2. Mean area of motoneurons $\left(\mu \mathrm{m}^{2}\right)$

\begin{tabular}{|c|c|c|c|c|c|c|c|c|c|c|}
\hline Age & $C_{1}$ & $\mathrm{C}_{2}$ & $\mathrm{C}_{3}$ & $\mathrm{C}_{4}$ & $\mathrm{C}_{5}$ & $\mathrm{C}_{6}$ & $C_{7}$ & $\mathrm{C}_{8}$ & mean & \pm S.D. \\
\hline 41 & 558.0 & 523.3 & 553.1 & 689.2 & 656.5 & 609.1 & 646.0 & 448.1 & 585.4 & 79.8 \\
\hline 47 & 504.5 & 519.7 & 459.6 & 726.9 & 662.9 & 665.5 & 650.6 & 577.6 & 595.9 & 94.6 \\
\hline 52 & 407.6 & 427.6 & 555.3 & 529.6 & 615.0 & 682.5 & 675.5 & 574.5 & 558.4 & 102.3 \\
\hline 54 & 585.8 & 768.7 & 624.5 & 648.0 & 652.9 & 698.3 & 902.8 & 765.1 & 705.8 & 102.5 \\
\hline 59 & 658.4 & 498.0 & 502.8 & 813.4 & 577.6 & 746.8 & 730.1 & 681.3 & 651.0 & 115.6 \\
\hline 59 & 479.4 & 408.8 & 558.4 & 759.6 & 706.2 & 756.9 & 723.5 & 674.4 & 633.4 & 134.2 \\
\hline 61 & 505.4 & 547.4 & 528.6 & 639.7 & 576.8 & 637.2 & 742.5 & 570.4 & 593.5 & 76.7 \\
\hline 65 & - & 515.9 & 703.1 & 1069.5 & 1000.1 & 917.1 & 729.9 & 887.6 & 831.9 & 192.3 \\
\hline 73 & - & 620.6 & 600.5 & 940.9 & 729.7 & 1031.4 & 1019.2 & 904.3 & 835.2 & 182.8 \\
\hline 78 & 582.9 & 639.9 & 745.1 & 781.2 & 771.5 & 813.4 & 762.1 & 749.4 & 730.7 & 78.1 \\
\hline 82 & - & 590.5 & 702.7 & 697.5 & 794.7 & 826.9 & 721.2 & 750.2 & 726.3 & 76.6 \\
\hline 88 & - & 684.8 & 1016.2 & 813.3 & 1032.4 & 524.3 & 942.6 & 853.7 & 838.2 & 184.0 \\
\hline
\end{tabular}


$41.2 \pm 16.0)$ per section. The regression analysis showed a correlation between age and the mean number of motoneurons only after 65 years (Table 1, Fig. 1: before 65 years, $r=0.37, P>0.3$; after 65 years, $r=-0.72, \mathrm{P}>0.1$ ).

\section{Mean Transverse Area of Motoneurons}

The average transverse area of motoneurons ranged from $407.6 \mu \mathrm{m}^{2}$ to $1,069.5 \mu \mathrm{m}^{2}$ (mean: $685.4 \pm 151.6 \mu \mathrm{m}^{2}$ ). The regression analysis showed no correlation between age and the mean area of motoneurons (Table 2, Fig. 2: before 65 years, $r=$ $0.60, \mathrm{P}>0.1$; after 65 years, $\mathrm{r}=-0.26, \mathrm{P}>0.5$ ).

\section{Total Transverse Area of Motoneurons}

The total transverse area of motoneurons ranged from $5,313.9 \mu \mathrm{m}^{2}$ to $87,699.1 \mu \mathrm{m}^{2}$ (mean: $29,259.6 \pm 14,895.7 \mu \mathrm{m}^{2}$ ). The scatter diagram with regression line is shown in Fig. 3. It shows two different phases: a slight increase in total area of motoneurons up to 65 years of age, followed by a sharp and continuous decrease (Table 3, Fig. 3:

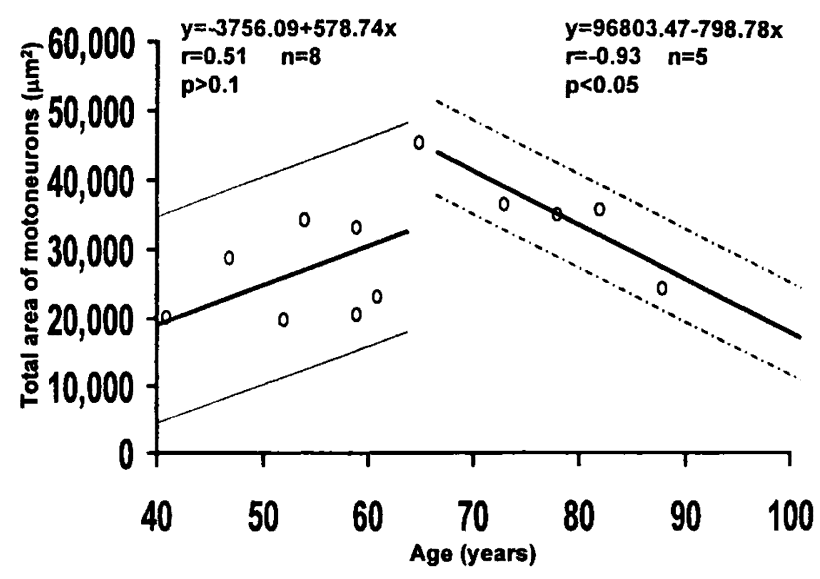

Fig. 3. Total transverse area of motoneurons in the human cervical cord. before 65 years, $\mathrm{r}=0.51, \mathrm{P}>0.1$; after 65 years, $\mathrm{r}=-0.93, \mathrm{P}<0.05)$.

\section{Discussion}

Rexed $^{7)}$ classified the spinal cord gray matter into 10 laminae which he numbered, roughly from dorsal to ventral. (The original study was conducted on the cat, but the data are applicable to other species as well.) Lamina IX consists of several distinct clusters of large somatic motoneurons that occupy somewhat different positions within the anterior gray horn at various spinal levels. The cervical enlargement contains a larger numbers of clusters made up of more numerous motoneurons. The anterior horn cells of this lamina are large multipolar neurons (soma diameter of 30 to $70 \mu \mathrm{m}$ ) with central nuclei and coarse Nissl bodies. These large motor cells, which innervate skeletal muscles, are referred to as alpha $(\alpha)$ motoneurons; scattered among them are smaller gamma $(\gamma)$ neurons that give rise to efferent fibers that emerge via the ventral root and innervate the contractile elements of the muscle spindle. Gamma efferent fibers play an essential role in the maintenance of muscle tone and bring the muscle spindle under control of spinal and supraspinal influences ${ }^{1,7)}$.

Many researchers have reported that the number and size of the motoneurons decreases with age. It should be noted that the results of this study are in general agreement with the report by Tomlinson et $a{ }^{8)}{ }^{8)}$ In their study, forty-seven spinal cords were examined at lumbar segments from subjects between 13 and 95 years old. No evidence of loss of motoneurons was found up to the age of 60 . But, there is increasing evidence of loss of motoneurons after that age. Cell loss appeared to be uniform throughout all the segments and not to be accompanied by any other striking morphological change.

Table 3. Total area of motoneurons $\left(\mu \mathrm{m}^{2}\right)$

\begin{tabular}{|c|c|c|c|c|c|c|c|c|c|c|}
\hline Age & $\mathrm{C}_{1}$ & $\mathrm{C}_{2}$ & $\mathrm{C}_{3}$ & $\mathrm{C}_{4}$ & $\mathrm{C}_{5}$ & $\mathrm{C}_{6}$ & $\mathrm{C}_{7}$ & $\mathrm{C}_{8}$ & mean & \pm S.D. \\
\hline 41 & 11718.3 & 17791.2 & 14380.0 & 33769.2 & 23633.1 & 15837.7 & 36177.8 & 6722.0 & 20003.7 & 10441.6 \\
\hline 47 & 13621.4 & 10913.2 & 7812.6 & 45069.9 & 52370.5 & 38599.7 & 29928.6 & 31188.7 & 28688.1 & 16535.6 \\
\hline 52 & 6520.9 & 7696.9 & 12217.2 & 26479.3 & 25828.3 & 30028.4 & 30399.1 & 18384.5 & 19694.3 & 9857.2 \\
\hline 54 & 26948.5 & 29980.0 & 22480.2 & 29158.4 & 26768.8 & 32119.6 & 49653.6 & 55089.7 & 34024.9 & 11757.4 \\
\hline 59 & 23042.7 & 10458.3 & 20612.6 & 53687.0 & 36963.1 & 61984.8 & 34314.3 & 21800.2 & 32857.9 & 17612.9 \\
\hline 59 & 10546.8 & 5313.9 & 15636.0 & 28103.3 & 35308.9 & 22706.1 & 27492.1 & 16860.6 & 20246.0 & 9978.1 \\
\hline 61 & 14152.4 & 29010.6 & 18500.1 & 25589.7 & 27687.9 & 31861.0 & 24503.0 & 11978.5 & 22910.4 & 7226.2 \\
\hline 65 & - & 15993.5 & 36562.4 & 87699.1 & 49004.8 & 57774.2 & 21897.7 & 46154.8 & 45012.4 & 23979.3 \\
\hline 73 & - & 17996.5 & 24021.7 & 66805.0 & 39403.8 & 36097.4 & 41788.2 & 28937.4 & 36435.7 & 15865.1 \\
\hline 78 & 25064.4 & 12157.9 & 35020.1 & 32809.2 & 41661.0 & 39042.0 & 56391.5 & 35223.8 & 34671.2 & 12777.0 \\
\hline 82 & - & 25983.6 & 25296.5 & 42549.3 & 45298.2 & 42171.1 & 36061.4 & 32260.3 & 35660.1 & 8119.0 \\
\hline 88 & - & 19174.1 & 22355.8 & 34158.1 & 22713.7 & 11010.9 & 16966.8 & 40978.6 & 23908.3 & 10305.6 \\
\hline
\end{tabular}


After research at level $C_{6}$ of the human spinal cord in twenty-four male cadavers, aged from 41 to 97 years without any accompanying pathological changes in the spinal cord, Zhang et al. ${ }^{9)}$ showed that a reduction in number and size of motoneurons in the human spinal cord is associated with neuronal degeneration and the loss of motoneurons during the aging process.

Our study revealed a sharp decrease in the total transverse area of the human cervical motoneurons after the age of 65 , which led us to consider two different phases, with that age as the boundary. Although the data regarding the mean number of motoneurons were not statistically significant, we can still see a tendency to decrease after the age of 65 . This, together with the definite reduction of the total transverse area, could induce us to think that motoneurons in the spinal cord tend to get smaller as people get older. However, closer analysis of the data shows that this is not true. The mean transverse area (Fig. 2) shows no sign of decrease after the age of 65 . We can therefore only conclude that there appears a kind of compensatory phenomenon: as the number of motoneurons decreases with age, the remaining ones tend to, on the contrary, incease in size, obviously in order to maintain their function.

\section{References}

1) Carpenter MB. Spinal cord: Gross anatomy and internal structure. In Carpenter, M.B. (ed): Core text of neuroanatomy, pp 57-82, Williams \& Wilkins, Baltimore, MD, 4th ed., 1991.

2) Duncan D. Incidence of mild degrees of atrophy in fasciculus gracilis. Arch Pathol 1938; 26:664-675.

3) Goto N. Discriminative staining methods for the nervous system: Luxol fast blue-periodic acid-Schiff-hematoxylin triple stain and subsidiary staining methods. Stain Technol 1987; 62:305-315.

4) Hara K. Changes by age group in the caudal level of termination of the spinal cord in Japanese adults. Acta Anat Nippon 1987; 62:329-333.

5) Kawamura Y, Okazaki H, O'Brien PC and Dyck PJ. Lumbar motoneurons of man: I) Number and diameter histogram of alpha and gamma axons of ventral root. J Neuropathol Exp Neurol 1977; 36:853-860.

6) Kawamura Y, Okazaki H, O'Brien PC and Dyck PJ. Lumbar motoneurons of man: II) The number and diameter distribution of large- and intermediate-diameter cytons in "motoneuron columns" of spinal cord of man. J Neuropathol Exp Neurol 1977; 36:861-870.

7) Rexed B. The cytoarchitectonic organization of the spinal cord in the cat. J Comp Neurol 1952; 96:415-495.

8) Tomlinson $\mathrm{BE}$ and Irving $\mathrm{D}$. The numbers of limb motor neurons in the human lumbosacral cord throughout life. J Neurol Sci 1977; 34:213-219.

9) Zhang C, Goto N, Suzuki M and Ke M. Age-related reductions in number and size of anterior horn cells at $\mathrm{C}_{6}$ level of the human spinal cord. Okajimas Folia Anat Jpn 1996; 73:171-178. 